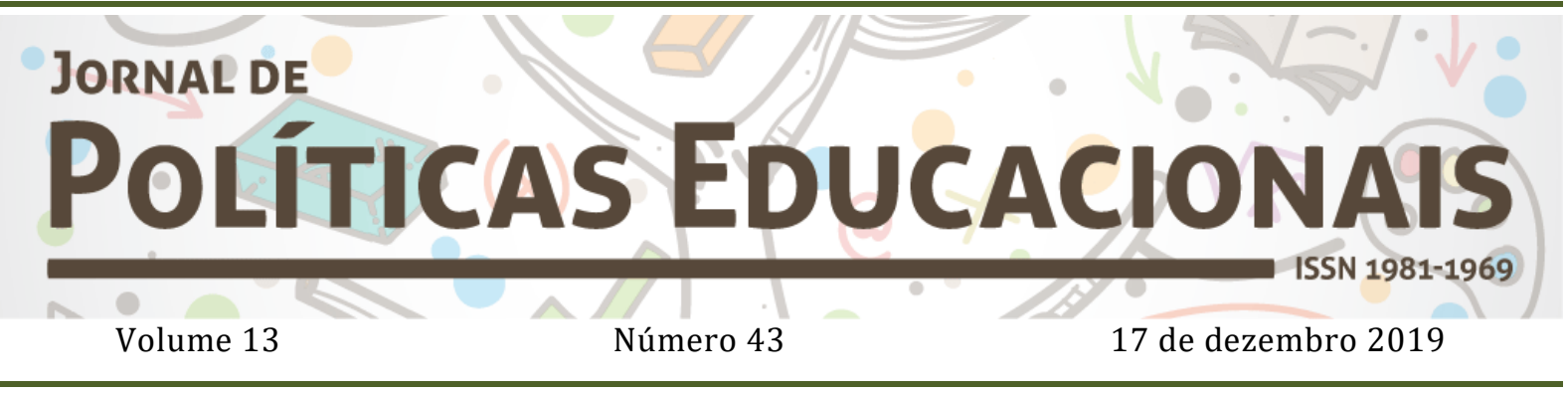

\title{
Burocracia educacional em interação com as famílias nos processos de matrícula escolar na cidade do Rio de Janeiro
}

\section{Burocracia educativa en interacción con las familias en los procesos de matriculación escolar en la ciudad de Río de Janeiro}

\section{Educational bureaucracy in interaction with families in school enrollment processes in the city of Rio de Janeiro}

\author{
Rodrigo Rosistolato ${ }^{1}$ \\ Ana Pires do Prado ${ }^{2}$ \\ Maria Muanis ${ }^{3}$ \\ Diana Cerdeira ${ }^{4}$
}

Citação: ROSISTOLATO, R.; PRADO, A. P. do; MUANIS, M; CERDEIRA, D. Burocracia educacional em interação com as famílias nos processos de matrícula escolar na cidade do Rio de Janeiro. Jornal de Políticas Educacionais. V. 13, n. 43. Dezembro de 2019.

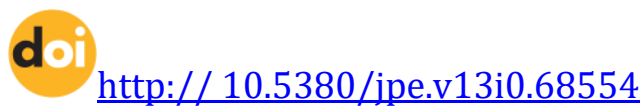

\begin{abstract}
Resumo
O objetivo do trabalho é apresentar os resultados de uma investigação sobre as relações entre a burocracia escolar e as famílias dos estudantes durante os processos de matrícula escolar na rede municipal da cidade do Rio de Janeiro. Nela, há escolas com diferentes desempenhos e reputações; por isso, há diferenças de demanda pelas vagas oferecidas.
\end{abstract}

\footnotetext{
1 Doutorado em Antropologia Social pela Universidade Federal do Rio de Janeiro, Brasil(2007) Professor Associado da Universidade Federal do Rio de Janeiro , Brasil. E-mail: rodrigo.rosistolato@gmail.com Orcid: https://orcid.org/0000-0002-4025-0632

${ }^{2}$ Doutorado em Antropologia Social e Cultural pelo Universidad Autonoma de Barcelona, Espanha(2006) Professora adjunta da Faculdade de Educação da Universidade Federal do Rio de Janeiro, Brasil. E-mail: anapprado@yahoo.com Orcid: https://orcid.org/0000-0002-5897-6503

${ }^{3}$ Doutorado em Sociologia pelo Instituto Universitário de Pesquisas do Rio de Janeiro, Brasil(2010) Professora Adjunta da Universidade Federal do Rio de Janeiro , Brasil. E-mail: maria.muanis@gmail.com Orcid: https://orcid.org/0000-0001-5187-6545

4 Doutorado em Educação pela Universidade Federal do Rio de Janeiro, Brasil(2015) Professora Adjunta da Faculdade de Educação da Universidade do Estado do Rio de Janeiro , Brasil. E-mail: dianacerdeira@yahoo.com.br Orcid: https://orcid.org/0000-0002-3623-4672
} 
Embora exista uma legislação específica regulamentando critérios para a realização da matrícula dos estudantes que inclui, inclusive, regras para desempate entre famílias no caso de maior demanda do que oferta, nossos dados permitem afirmar que existem diferentes estratégias utilizadas pelas famílias para escolher e acessar as melhores escolas, ora regidas exclusivamente pelo acompanhamento das regras e normas da regulamentação de matrícula, ora através do contato pessoal com profissionais da burocracia estatal e/ou com pessoas conectadas a eles. A análise desse cenário de escolha e acesso das escolas revela um conjunto de sociabilidades entre as famílias e o Estado, representado, nesse caso, pela burocracia escolar. Nosso objetivo é descrever e analisar esse cenário e os resultados objetivos das ações empreendidas pelas famílias e pelos profissionais da escola. Concluímos que as famílias que estabelecem contatos pessoais diretos ou indiretos com a burocracia escolar têm maiores chances de acessar as vagas nas escolas mais disputadas. Isso ocorre porque as ações discricionárias da burocracia, em conjunto com as ações familiares, definem as trajetórias dos estudantes com base em critérios por vezes antagônicos à lógica republicana que deveria organizar a distribuição de vagas em escolas.

Palavras-chave: burocracia escolar, famílias, matrícula, escola republicana.

\begin{abstract}
The paper presents the results of a research on the relations between the school bureaucracy and the students' families during the enrollment processes in the public school municipal network of Rio de Janeiro in which there are schools with different performances and reputations; therefore, there are differences in demand for the places offered. Although there is specific legislation for enrollment that even includes rules for tie breaker between families in case of greater demand than supply, our data allow us to state that there are different strategies used by families to choose and access the best schools, sometimes governed exclusively by monitoring registration rules and regulations, sometimes through personal contact with state bureaucracy professionals and/or those connected with them. The analysis of this spaces of choice and access to schools reveals a set of sociability between families and the state. Our goal is to describe and analyze this context and the objective results of actions taken by families and school professionals. We conclude that families who establish direct or indirect personal contacts with the school bureaucracy are more likely to access places in the most contested schools. This is because the discretionary actions of the bureaucracy, together with family actions, define students' trajectories based on criteria that are sometimes antagonistic to the republican logic that should organize the distribution of places in schools.
\end{abstract}

Keywords: education, educational policy, school enrollment, school choice.

\title{
Resumen
}

El artículo presenta los resultados de una investigación sobre las relaciones entre la burocracia escolar y las familias de los estudiantes en el proceso de inscripción en la red municipal de Río de Janeiro. La red tiene escuelas con distintos rendimientos y reputaciones y, por eso, hay demandas distintas por las plazas ofrecidas. Aunque exista una legislación específica para la inscripción, que incluye las reglas para el desempate entre las familias en caso de una mayor demanda que oferta, nuestros datos nos permiten afirmar que las familias utilizan diferentes estrategias para elegir y acceder a las mejores escuelas. Por veces siguen exclusivamente las reglas y reglamentos de registro, otras veces utilizan el contacto personal con profesionales de la burocracia estatal o aquellos 
relacionados a ellos. El análisis de este escenario de escoja y acceso a las escuelas revela un conjunto de sociabilidad entre las familias y el estado. Nuestro objetivo es describir y analizar este escenario y los resultados objetivos de las acciones tomadas por las familias y por los profesionales de la escuela. Llegamos a la conclusión de que las familias que establecen contactos personales directos o indirectos con la burocracia escolar tienen más probabilidades de acceder a las escuelas más disputadas. Las acciones discrecionales de la burocracia, junto con las acciones familiares, definen las trayectorias de los estudiantes con base en criterios, que en determinadas ocasiones son antagónicos a la lógica republicana que debería organizar la distribución de plazas en las escuelas.

Palabras clave: educación, política educativa, matriculación escolar, elección escolar.

\section{INTRODUÇÃO}

O Laboratório de Pesquisa em Oportunidades Educacionais (LaPOpe) tem investigado, nos últimos anos, os processos formais e informais de matrícula escolar na rede municipal da cidade do Rio de Janeiro. No primeiro momento, pesquisamos as estratégias familiares para a escolha e acesso às escolas. Posteriormente, analisamos a gestão das políticas de matrícula nas unidades escolares. No presente artigo, apresentamos as ações familiares durante a matrícula e a perspectiva dos gestores escolares sobre esses processos. Nossas análises revelaram aspectos das relações entre as famílias e as escolas que permitiram relativizar, dentre outras questões, o mito da omissão parental.

Acredita-se, no senso comum e em parte do debate público sobre a escola, que as famílias das camadas populares não estão diretamente envolvidas com a educação de seus filhos, deixando-a exclusivamente a cargo das escolas. Esse mito já foi problematizado por outros autores (LAHIRE, 1997; ZAGO, 2000) e nossos dados também evidenciam que as famílias envolvem-se diretamente com a escolarização de seus filhos. Entretanto, por vezes, esse envolvimento é limitado pelas dinâmicas existentes entre as escolas, as famílias e as redes de ensino, principalmente quando ocorrem disputas por escolas em que a demanda é maior do que a oferta de vagas.

Nesse cenário, nosso argumento é que, embora existam ações diretas das famílias de camadas populares com vistas a promover o que consideram a melhor educação para os seus filhos, elas são limitadas e/ou constrangidas por atitudes discricionárias realizadas por parte da burocracia estatal. Como resultado dessas relações entre as famílias e a burocracia tem-se, por um lado, a manutenção de um sistema estratificado por desempenho e reputação; por outro, a produção de desigualdades educacionais no interior de escolas públicas. Aqui, optamos por apresentar uma descrição e um conjunto 
ROSISTOLATO, R.; PRADO, A. P. do; MUANIS, M; CERDEIRA, D. Burocracia educacional em interação com as famílias nos processos de matrícula escolar na cidade do Rio de Janeiro

de análises sobre as relações das famílias dos estudantes com as burocracias escolares de duas escolas de alto desempenho e boa reputação, localizadas na zona sul e na zona norte da cidade do Rio de Janeiro. Em ambas as escolas a demanda por vagas é maior do que a oferta. Conforme demonstraremos, há um conjunto de ações familiares legitimadas e/ou constrangidas pela burocracia municipal no decorrer da distribuição das vagas nas duas escolas.

Na sequência do texto, apresentaremos o debate - nacional e internacional - sobre burocracia e discricionariedade, descreveremos a legislação de matrícula na cidade do Rio de Janeiro e apresentaremos as visões dos gestores e das famílias que buscam vagas nas escolas analisadas.

No decorrer das descrições será possível compreender como os gestores pensam e realizam suas ações referentes à matrícula escolar, além das relações estabelecidas com as famílias que usam estratégias para acessar as vagas disponíveis em ambas as escolas. As narrativas das famílias também revelam detalhes das relações de proximidade desenvolvidas com os gestores no decorrer dos processos de matrícula. Ao final, revelaremos um intrincado sistema de relações que, por vezes, contradiz alguns pressupostos elementares de um sistema republicano de acesso às escolas, quais sejam: a garantia de isonomia no decorrer da distribuição de bens públicos universais e a impessoalidade das ações burocráticas.

\section{BUROCRACIA E DISCRICIONARIEDADE}

O debate sobre a relação família/escola pode ser considerado um dos principais alicerces da sociologia e da antropologia da educação no Brasil e no mundo. Desde a divulgação dos relatórios Coleman (1966), Plowden (DEPARTMENT OF EDUCATION AND SCIENCE,1967) e das pesquisas do Institut National d'Études Démographiques - INED (1962-1972), a hipótese sobre a correlação entre o perfil socioeconômico familiar e o desempenho acadêmico dos alunos tem sido testada exaustivamente e conduzido a resultados semelhantes sobre a influência direta do background familiar no rendimento e na trajetória escolar dos estudantes.

Há, inserida nesse debate, uma discussão mais pontual sobre o envolvimento direto das famílias, no plano das ações e das estratégias, na escolarização das crianças. Nesse sentido, uma das principais ações a serem notadas é exatamente a escolha do 
ROSISTOLATO, R.; PRADO, A. P. do; MUANIS, M; CERDEIRA, D. Burocracia educacional em interação com as famílias nos processos de matrícula escolar na cidade do Rio de Janeiro

estabelecimento escolar em que as crianças irão estudar (NOGUEIRA, C. M. M et al, 2015). Esse debate sustenta a premissa de que o perfil da escola em que a criança será matriculada contribuirá diretamente para maior ou menor acesso aos bens escolares stricto sensu: incorporação de saberes disciplinares, de noções e de atributos considerados fundamentais para a vida em sociedade.

No caso específico da cidade do Rio de Janeiro, já há literatura científica suficiente para afirmar que a rede municipal de educação é estratificada, e que, por conta disso, há disputas entre as famílias para acessar as melhores escolas. Em sentido convergente, também ocorrem ações diretas da burocracia educacional na organização da distribuição não equitativa de crianças em escolas (BRUEL; BARTHOLO, 2012; COSTA et al, 2013; CARVALHO, 2014). A estratificação interna da rede cria um cenário em que, embora todas as escolas sejam públicas e de acesso universal, acabam por oferecer trajetórias formativas diferentes para as crianças, configurando um sistema reprodutor e produtor de desigualdades sociais.

A reprodução das desigualdades de origem social no interior das escolas impõe uma série de desafios para a equalização do sistema. As pesquisas anteriores realizadas no Rio de Janeiro revelam uma gama de elementos relacionados à construção das escolas de prestígio e à seletividade do alunado e desempenho das escolas (COSTA, 2008). Faltava-nos, no entanto, maior conhecimento sobre as ações diretas - discricionárias dos agentes escolares, especificamente os gestores, na consolidação e manutenção das diferenças entre as escolas; e também de processos internos de seleção do alunado. Nosso argumento principal é que essas ações não somente reproduzem desigualdades sociais de origem, mas também produzem novas desigualdades durante os trajetos formativos experimentados pelos estudantes.

A partir do momento em que decidimos estudar os processos de produção de desigualdades no interior das escolas, optamos pela análise das ações de gestores relacionadas à matricula das crianças nos estabelecimentos escolares. Naquele momento, já havíamos trabalhado com a perspectiva das famílias sobre a matrícula escolar (ROSISTOLATO, 2015; ROSISTOLATO et al, 2016). Daí a ideia de comparar as visões das famílias com aquelas apresentadas pelos gestores. Partíamos da hipótese, sustentada pela literatura internacional, da existência de ações discricionárias por parte de gestores de políticas públicas no decorrer de sua implementação (LIPSKY, 1980; MAYNARD-MOOD; MUSHENO, 2003). Essa hipótese tem sido testada e confirmada no Brasil no campo da 
saúde (LOTTA, 2015) e também no campo da educação (OLIVEIRA; CARVALHO, 2017; ALMEIDA, 2019).

Lipsky (1980) afirma que a análise de implementação de políticas públicas deve pautar-se na observação e interpretação das ações diretas dos agentes que estão na ponta dos sistemas, travando contato direto com o público atendido pelas políticas. Esses burocratas são vistos como policy makers, pois suas interações com o público e suas ações no processo de implementação das políticas interferem diretamente em seu formato final.

Embora façam parte de uma estrutura burocrática, com normas e regras, esses agentes, nas interações face a face com o público, atuam necessariamente com discricionaridade (Pires, Lotta e Junior, 2018). Entende-se por discricionariedade o grau de poder, autoridade e legitimidade dos burocratas para adaptarem à legislação vigente ou arbitrarem nos casos não previstos pelas regras.

As decisões tomadas por esses burocratas impactam diretamente no acesso dos cidadãos aos bens públicos, podendo favorecer ou desmerecer determinados cidadãos no que concerne o usufruto de determinada política pública.

Nessa perspectiva, analisando as escolas, os gestores são burocratas cujas ações discricionárias no ato da matrícula contribuem com a definição de trajetórias escolares, para usar os termos cunhados por Brandão et al (2005), "virtuosas" ou "viciosas". Mas como compreender as ações discricionárias na esfera pública, inseridas no Estado republicano? Estudos recentes sobre as características do Estado Moderno, seguindo a teoria weberiana, demonstram a permanência de relações simbióticas entre o patrimonialismo e a burocracia nos Estados modernos (ERMAKOFF, 2011; KISER AND SACKS, 2011; CHARRAD, 2011; HANSON, 2011). As ações discricionárias não são necessariamente patrimonialistas, mas, assim como o patrimonialismo, colocam desafios interpretativos para a análise das dinâmicas dos Estados modernos, quando consideramos especificamente a distribuição de bens e serviços sociais.

Ermakoff (2011) argumenta que as regras burocráticas podem acomodar e até abrir espaço para as práticas patrimoniais quando, por exemplo, o burocrata estabelece uma relação de troca de favores, personalização das regras e estabelecimento de critérios próprios para a tomada de decisões, sem explicações e sem receio de sanções. Essa análise permite, portanto, pensar os gestores como burocratas que fazem parte de uma estrutura burocrática racional-legal com regras e normas legalmente instituídas e impessoais, mas com espaços para discricionariedade, com práticas e lógicas patrimonialistas, ou então 
construídas nas brechas da racionalização, por vezes consolidando-se como lógica tradicional dentro do Estado racional.

Estudos anteriores já demonstraram como estudantes com perfis equivalentes em termos de nível socioeconômico, capital cultural, local de moradia e pertencimento a redes sociais têm trajetórias diferentes resultantes das ações de suas famílias e dos gestores escolares (Rosistolato, Pires do Prado \& Costa, 2014; Rosistolato et al, 2016). Também há pesquisas que indicam como os gestores tendem a perceber as escolas como "suas" agindo e administrando os estabelecimentos de ensino de forma autônoma em relação à rede à qual pertencem (Pires do Prado, 2009, 2006; Encarnação, 2007). A análise de Rosistolato, Pires do Prado, Cerdeira e Muanis (2018) evidencia a diversidade de interpretações das regras de matrícula e de ações discricionárias dos gestores nesse processo. Esses burocratas não só decidem (quando há oportunidade) sobre os alunos que realizarão a matrícula nas suas escolas, como influenciam, no momento das interações, as escolhas das famílias. É importante salientar que uma ação discricionária não é necessariamente patrimonialista, mas, por vezes, a lógica patrimonialista orienta tais ações. No decorrer das descrições será possível identificar ambos os elementos nas ações dos gestores em relação com as famílias.

As análises têm por base um conjunto de entrevistas em profundidade realizadas com gestores de matrícula em escolas municipais. Esses dados, em conjunto com entrevistas já realizadas com as famílias que buscavam matricular seus filhos, permitiram o refinamento de nossa abordagem sobre a implementação da política de matrícula escolar no Rio de Janeiro. Na sequência do texto, apresentaremos a regulamentação de matrícula e os dados referentes às duas escolas de alto desempenho e reputação positiva analisadas.

\section{REGULAMENTAÇÃO DE MATRÍCULAS}

A regulamentação do sistema de matrículas da rede de ensino do município do Rio de Janeiro é promulgada anualmente através de portarias ou resoluções. Alterações são realizadas a cada ano, seja para ajustes de calendário de matrículas, seja para a criação de normas ausentes nas versões anteriores. Nos documentos, identificam-se três modalidades de matrícula: a inicial, a renovada e a que ocorre por transferência.

A matrícula inicial é realizada pelos responsáveis de alunos que nunca estudaram na rede municipal. Para aqueles que ingressam antes do início do período letivo, esta 
matrícula deve ser efetuada por meio da internet, através da inscrição do aluno em um sistema digital da prefeitura, em que há a possibilidade de escolha de até cinco estabelecimentos de ensino. 0 aluno que não se enquadra nos critérios de atendimento prioritário é alocado pelo sistema, de forma aleatória, em uma das escolas selecionadas por sua família. Aqueles que ingressam após o fim do período da matrícula digital devem realizar a matrícula diretamente nas unidades escolares.

A matrícula renovada é efetuada para aqueles que já integram a rede e permanecem na mesma escola ou são remanejados para estabelecimentos que atendem o segmento de ensino subsequente quando a própria escola não o possui. 0 remanejamento ocorre na mudança de segmento de ensino e, portanto, se concentra em dois momentos da educação básica: da educação infantil para os anos iniciais do ensino fundamental e desses para os anos finais.

A transferência interna destina-se a alunos que queiram mudar de escola. Pode ocorrer tanto pela matrícula digital - no período do ano em que ela está disponível - como ao longo de todo o ano letivo, quando os responsáveis pelo aluno devem procurar diretamente a escola almejada.

Embora a implementação do sistema de matrículas digital, em 2010, tenha garantido a impessoalidade na matrícula inicial e na transferência, por alocar os alunos nas escolas a partir de critérios públicos previamente estabelecidos ${ }^{5}$, o remanejamento e as transferências internas ou matrículas iniciais realizadas diretamente nas unidades escolares, sobre os quais não há orientações nos documentos oficiais, possibilitam maior grau de discricionariedade dos gestores escolares.

Em relação ao remanejamento, a regulamentação da matrícula menciona que "§1으 Os alunos matriculados nas Unidades Escolares em que não haja segmento subsequente terão suas matrículas garantidas por meio de remanejamento". A transferência interna, por sua vez, após o período de matrícula digital, "deve ser realizada diretamente nas unidades escolares e estará sujeita à disponibilidade de vagas" (Resolução no 25, de 24 de outubro de 2017).

A regulamentação também determina as responsabilidades do gestor nos procedimentos de matrícula. Como pode ser observado abaixo, as responsabilidades

\footnotetext{
${ }^{5}$ Deve-se mencionar, contudo, que não há publicização de como o sistema realiza as alocações prioritárias e a alocação aleatória dos alunos. Há, definidos na resolução, apenas os critérios para definição das prioridades legais.
} 
estão circunscritas à confirmação da matrícula nos prazos estabelecidos e à atualização do sistema de controle acadêmico.

\footnotetext{
É de responsabilidade do Diretor da Unidade Escolar:

Providenciar a inclusão da confirmação de matrícula dos alunos de transferência interna no Sistema Matrícula Rio/Gerencial, tendo como data limite para realizála o dia 08/12/2017, impreterivelmente, para alunos de creche; o dia 11/12/2017, impreterivelmente, para alunos de Pré-escola; o dia 16/12/2017, impreterivelmente, para os alunos de Ensino Fundamental e EJA.

Providenciar a inclusão da confirmação de matrícula dos novos alunos no Matrícula Rio/Gerencial, até o dia 19/01/2018, impreterivelmente, para alunos de Pré-escola; o dia 23/01/2018, impreterivelmente, para os alunos de Ensino Fundamental e EJA.

Providenciar a inclusão da confirmação de matrícula dos novos alunos da 1 a Divulgação no Matrícula Rio/Gerencial, até o dia 08/12/2018, impreterivelmente, e até o dia 15/12/2018 para alunos de Creche.

Manter o Sistema de Controle Acadêmico e/ou Sistema de Gestão Acadêmica atualizados, registrando as confirmações de eventuais novas matrículas durante todo o ano letivo.
}

Deve-se ressaltar que, ao longo da última década, o período em que as matrículas iniciais ou as transferências internas ocorrem pelo sistema digital vem se ampliando. Até 2015, ele vigorava até o fim de janeiro. Em 2016, entretanto, ele passou a funcionar até final de março. A expansão desse prazo, que agora se encerra aproximadamente dois meses após o início das aulas, inibiu a ação discricionária dos gestores na seleção dos alunos.

A ausência de regulamentação no processo de remanejamento e nas transferências internas e matrículas iniciais nas escolas permite um papel ativo dos gestores na distribuição de vagas, especialmente por parte daqueles que trabalham nas unidades escolares de maior prestígio. Nessas escolas, onde a demanda por vagas é maior que oferta, os gestores atuam selecionando o perfil do alunado que ali ingressará por estratégias que acontecem em dois momentos: (i) no remanejamento, via conexões com os diretores das escolas dos segmentos precedentes e (ii) na transferência interna ou na matrícula inicial realizadas presencialmente nas unidades durante o ano letivo, através de ajustes no número de vagas que ocorrem de acordo com o perfil do aluno que está pleiteando a vaga.

\section{METODOLOGIA}

Nesse trabalho, serão analisadas entrevistas realizadas com os gestores e com famílias sobre os procedimentos de matrícula. Para a análise das visões dos gestores, 
utilizaremos as entrevistas de dois gestores de escolas de $2^{\circ}$ segmento, ambas com alto desempenho e boa reputação. Uma escola localiza-se na zona sul do Rio de Janeiro e, portanto, administrativamente, está circunscrita à 2a CRE (Coordenadoria Regional de Educação) ${ }^{6}$. A outra situa-se na zona norte, pertencendo à $4^{\text {a }}$ CRE. Ambos os estabelecimentos atendem a alunos de $2^{\circ}$ segmento do ensino fundamental e recebem, no processo de remanejamento, alunos das escolas dos anos iniciais que se localizam próximas a eles.

As duas Coordenadorias Regionais de Educação - a $2^{\mathrm{a}}$ e a $4^{\mathrm{a}}$ CRE - foram escolhidas porque são estratificadas em nível socioeconômico e desempenho escolar, considerando a diversidade e a localidade do público que atendem. Nessas CREs, escolhemos dois polos de matrícula. Os polos reúnem escolas localizadas próximas geograficamente que se organizam para alocação de estudantes nos períodos de matrícula no final de um ano letivo. Analisaremos duas entrevistas com o secretário escolar da escola da 2a CRE, realizadas em 2014 e em 2016, e uma com a diretora da escola da 4a CRE em 2017.

Para análise das visões das famílias sobre o processo de matrícula e da ação dos gestores nesse procedimento, utilizaremos o material de quatro entrevistas realizadas com as famílias de estudantes remanejados do $1^{\circ}$ para o $2^{\circ}$ segmento, no final do ano de 2012. Selecionamos quatro casos exemplares que indicaram a ação direta dos gestores das escolas nos procedimentos de matrícula, tanto no processo de remanejamento como na transferência interna. Das quatro famílias entrevistadas, duas eram da $2^{\text {a }}$ CRE e as outras duas eram da $4^{\underline{a}}$ CRE. Um caso da $2^{\text {a }}$ CRE demonstra a discricionariedade da gestão no período do remanejamento e o outro ressalta a ação dos gestores escolares na transferência interna. Já nos casos da 4⿳亠丷厂 $\mathrm{CRE}$, ambos são relativos ao remanejamento, também demonstrando a ação discricionária dos gestores.

\section{AS VISÕES E AS ESTRATÉGIAS DAS FAMÍLIAS E DOS GESTORES ESCOLARES NOS PROCESSOS DE MATRÍCULA}

A demonstração das ações familiares e dos níveis de discricionariedade dos gestores das escolas será realizada com base em uma descrição densa da estrutura das escolas, seguida pela perspectiva das famílias e, ao final, dos gestores. No decorrer da narrativa será possível perceber as minúcias das estratégias de ambos os atores -

\footnotetext{
${ }^{6}$ A Secretaria Municipal de Educação do Rio de Janeiro está dividida em onze CREs.
} 
familiares e gestores - no decorrer do processo de matrícula. É importante salientar que trabalhamos com a memória de todos os entrevistados, e consequentemente com os recortes que eles próprios estabelecem quando narram suas ações orientadas para a matrícula dos estudantes na rede. Conforme explicamos na metodologia, os casos descritos são exemplares porque revelam regularidades presentes no conjunto das entrevistas realizadas.

\subsection{A ESCOLA RUBI7}

A Escola Municipal Rubi localiza-se na zona sul do município do Rio de Janeiro. Tem ao todo 730 alunos e 35 docentes. Oferece o $1^{\circ}$ e o $2^{\circ}$ segmento do Ensino Fundamental, funcionando nos turno matutino e vespertino. A escola possui alunos que estão no nível III do Indicador de nível socioeconômico das escolas da educação básica (Inse/Inep) ${ }^{8}$. Isso significa que, além de bens elementares, como banheiro e até dois quartos para dormir, os alunos e suas famílias possuem televisão, geladeira, dois ou três telefones celulares. A renda familiar mensal está entre 1 e 1,5 salários mínimos; e seus responsáveis completaram o ensino fundamental ou médio.

A escola Rubi recebe alunos cujos pais, em sua maioria, possuem nível de escolaridade superior ao da média da CRE. Os professores são mais qualificados que a média da CRE (todos têm nível superior, mas a maioria tem especialização ou pósgraduação) e seu IDEB no $2^{\circ}$ segmento é superior à média da CRE e do município. 0 desempenho dos alunos na Prova Brasil em Língua Portuguesa e Matemática em 2017 é superior a $80 \%$ das escolas do município.

\subsubsection{A VISÃO DAS FAMÍlIAS SOBRE A AÇÃo DOS GESTORES NA MATRÍCULA ESCOLAR}

O aluno Antônio em 2013 tinha 12 anos e foi matriculado no 6ํㅜ ano na Escola Rubi. Sua mãe, Cátia, tinha 31 anos, se declarou parda e trabalhava como doméstica e babá com carteira assinada. Ela concluiu o ensino fundamental. Sobre a opção de colocar o filho na Escola Rubi, Cátia declarou que a escola de $1^{\circ}$ segmento em que ele estudava ofereceu, no

\footnotetext{
${ }^{7}$ Os nomes das escolas e dos entrevistados são fictícios.

${ }^{8}$ Dados obtidos no site do INEP: www.inep.gov.br, acesso em 14 de maio de 2019.
} 
período do remanejamento, três possibilidades, dentre as quais a escola desejada pela família: a Escola Rubi. Para Cátia "ela [a escola] que faz a transferência e aí ela dá opções de escola para gente escolher. Aí, ela vai lá e faz a transferência e matrícula; faz tudo, entendeu?".

A responsável indicou que, mesmo se essa escola não estivesse na lista de opções para o remanejamento, ela tentaria uma vaga indo diretamente à unidade escolar pleiteála, assim como fizera para sua filha mais velha.

Entrevistada: Não. Assim, mesmo se a escola não desse a opção da Rubi, eu ia tentar uma vaga para ele lá.

Entrevistadora: Você ia tentar?

Entrevistada: $E_{\text {. }}$

Entrevistadora: [...] Como que a senhora ia tentar a vaga [na escola Rubi]?

Entrevistada: Ah, eu ia lá para poder ver se tinha vaga. Porque assim, quando a gente vai lá eles pedem... A gente deixar o nome e aí eles mandam a gente ir. Antes, para minha filha, quando eu fui tentar uma vaga lá, eu tive que dormir na fila de um dia para outro para mim conseguir uma vaga, porque eles dão uma senha para a gente poder tentar, né? Não vai conseguir.. A gente não tem certeza se vai conseguir ou não, porque assim primeiro a preferência do Rubi é para... As vagas são para quem veio transferido de outra escola, entendeu?

Entrevistadora: Entendi.

Entrevistada: E a minha filha no caso não teve... A escola que ela estudava não tinha isso, de eles mesmos fazer em transferência...

Entrevistadora: Entendi.

Entrevistada: Aí eu tive que dormir lá na fila de um dia para o outro; ficava um guarda lá, eles davam a senha... Quando dava certa hora eles davam a senha pra gente não ficar lá a madrugada toda, entendeu?

Entrevistadora: Ah, entendi. Mas eles davam a senha e a senhora voltava para casa e depois ia lá?

Entrevistada: É, aí voltava para lá às seis horas da manhã porque começava atender às sete.

A mãe de Antônio, a partir de sua experiência com a filha mais velha, assinala que, para obter vagas em determinadas escolas, principalmente aquelas de alto prestígio, os pais precisam ter contato direto com a direção. Ela indica que as chances de conseguir a vaga na escola desejada aumentam se ela for pessoalmente à unidade escolar, seja entrando em uma fila ou tendo o nome em uma lista de espera. É importante salientar que, de acordo com a nova regulamentação de matrícula, não há mais filas para a obtenção de vagas. Todo o sistema foi informatizado e o sorteio das vagas é aleatório. A entrevistada rememora a experiência que viveu com a filha mais velha e entende que poderia reproduzi-la com Antônio. Ela também contava com a possibilidade de dialogar com os funcionários da escola em busca de uma vaga.

0 trecho indica também distinções entre as ações discricionárias e 
patrimonialistas dos gestores no período em que as vagas eram garantidas na fila de espera e o que ocorre no sistema digital atual. A narrativa demonstra que a espera na fila, com senha para o atendimento, possibilitava maior interação com os gestores da escola. Atualmente, mesmo com o sistema digital, a mãe assinala que tentaria a vaga indo diretamente à escola. Ela indica sua crença na possibilidade de atuação direta dos burocratas da escola no período das transferências. Em síntese, parte do princípio de que, caso não conseguisse a vaga por sorteio, teria como buscá-la em interação direta com os gestores da escola, após o remanejamento e o sorteio de vagas. Outra entrevistada, Kelly, também apresenta uma crença convergente com à apresentada por Cátia.

0 relato de Kelly, mãe de Luca, demonstra a ação discricionária e patrimonialista dos gestores da Escola Rubi no processo de transferência. Luca tinha 12 anos em 2013 e estava no $7^{\circ}$ ano da Escola Rubi, a escola escolhida por sua mãe. Kelly completou o ensino médio e é trabalhadora do lar. Ela relatou que gostaria que Luca estudasse ali desde o $1^{0}$ ano, pois tinha uma "imagem boa" da escola; outros pais e amigos "falavam bem". $\mathrm{Na}$ época, ela não conhecia pessoalmente o funcionário Jean, mas já tinha ouvido falar: "qualquer coisa procura o [Jean]"; "você quer fazer alguma coisa lá na [Escola], quer uma vaga, fala com o [Jean] que ele consegue pra você".

Ela decidiu matriculá-lo na Escola Rubi no 1ํo ano, embora já tivesse uma vaga garantida em outra escola. Segundo a responsável, na época, era preciso "dormir na fila", por isso seu marido chegara às três horas da manhã na escola. A diretora chegou às nove horas, perguntou quem estava na fila para a alfabetização e disse que não tinha vaga. Kelly decidiu retornar à escola e falar com o funcionário Jean, que teria sugerido: "depois que começarem as aulas você vem aqui, se tiver desistência a gente coloca ele".

Kelly ficou receosa de não conseguir a vaga no início do ano letivo. Assim, matriculou seu filho em uma escola "para garantir" e depois retornou à Escola Rubi para falar com o Jean. Perguntou: “[Jean], você tem uma vaga pra mim?” e ele respondeu: “Ah, lembrei de você, eu tenho uma vaga pra você".

Kelly disse ser "muito agradecida a ele" e quando alguém a pede uma ajuda para conseguir uma vaga, ela diz: "procura o [Jean] que ele vai dar solução pra você; se tem, ele vai dizer 'tem sim', se não...". E complementa: "se você parar ali na frente da escola, na entrada ou na saída, você pode perguntar, não vai ter uma pessoa que vai falar mal dele", "é aquela pessoa que te encontra na rua, sabe seu nome, nome do seu filho, ele é muito legal mesmo". 
ROSISTOLATO, R.; PRADO, A. P. do; MUANIS, M; CERDEIRA, D. Burocracia educacional em interação com as famílias nos processos de matrícula escolar na cidade do Rio de Janeiro

Segundo Kelly, o funcionário Jean a ajudou também a mudar o turno do Luca. Inicialmente o estudante estava matriculado na turma da manhã, mas a mãe queria o turno da tarde. Ao falar com o Jean, ele anotou o nome do Luca e o colocou na turma da tarde. A mãe disse: "Quem salvou? Santo [Jean]!" e complementa: "ainda bem que tem ele pra salvar a escola".

Os dois processos narrados pelas mães indicam a ação discricionária do gestor no período de transferências. No caso de Cátia, mesmo com o sistema digital impessoal, a mãe acreditava que conseguiria a vaga indo diretamente à escola. A experiência anterior de ficar na fila com senha de atendimento, indica a possibilidade de atuação pessoal do burocrata da escola no período das transferências. Já o relato de Kelly demonstra que ela só conseguiu a vaga para seu filho por causa da sugestão do gestor de voltar à escola após o início das aulas. Nesse caso, o gestor "ter lembrado" da mãe e ela o avaliar como "um santo" é um indicador das ações discricionárias no período das transferências. As trajetórias das crianças, portanto, foram diretamente influenciadas pelas relações que suas mães estabeleceram com a burocracia municipal, o que revela que o caráter de impessoalidade previsto para a burocracia enquanto tipo ideal, nos casos específicos analisados, não foi considerado.

\subsubsection{GESTOR E AS AÇÕES DISCRICIONÁRIAS}

Jean é um secretário administrativo de 43 anos de idade que trabalha na escola Rubi há 24 anos. As entrevistas realizadas com o gestor em 2014 e em 2016 indicam que o período de maior ação discricionária ocorre durante as transferências internas e nas matrículas iniciais. Ambas estão sob responsabilidade das unidades escolares e são realizadas presencialmente nas escolas.

Em sua entrevista (2014), o gestor explica que o processo de remanejamento ocorre em várias etapas: primeiro a escola verifica quantas vagas possui - em função do pedido de transferência de alguns alunos que saem ao longo do ano para outras escolas e também da estimativa de alunos reprovados. Depois desse período, acontece uma reunião com a assessoria da CRE e os diretores das escolas de um mesmo polo. Nesse momento, conhecendo o número de vagas da escola de $2^{\circ}$ segmento e a quantidade de alunos concluintes das escolas de $1^{\circ}$ segmento, a assessoria da CRE realiza o remanejamento. $\mathrm{Na}$ sequência, encaminha as vagas restantes para o sistema de matrícula digital. 
Em entrevista realizada em 2016, Jean explica que a escola de $1^{\circ}$ segmento que encaminha os alunos para a E.M. Rubi, encaminha também para outras escolas próximas. As diretoras das escolas do $1^{\circ}$ segmento seriam as responsáveis por definir os critérios para encaminhar para a E.M. Rubi ou para as outras escolas de $2^{\circ}$ segmento do polo. De acordo com ele, quando há mais famílias optando por uma escola do que vagas disponíveis, elas realizam um sorteio ou outra forma de seleção. Citando especificamente a E.M. Citrino, ele explica como ocorre a distribuição dos alunos:

Jean: Tem na escola dela, ela é da EM Citrino. Ela tem setenta alunos pra remanejar de sétimo ano. (...) cinco vão ficar reprovados. Então, ela tem sessenta e cinco.(...). Desses sessenta e cinco, ela separou "trinta pra Rubi e trinta e cinco pra Ametista.". Chega na reunião dos diretores lá pra ver as turmas, e vê que ela não tem essas trinta e cinco vagas. Ela faz o sorteio. Foram vinte e cinco pra Rubi. Cinco que queriam, não conseguiram. Começou o ano letivo, ela pode ir na Rubi. Se saiu, desses vinte e cinco, um foi pra Pedro II ou conseguiu vaga num colégio particular ou o pai, que trabalhava aqui e saiu, conseguiu vaga perto de casa...ela pode ir. Tendo vaga, a gente faz.

O gestor confirmou a possibilidade de obtenção da vaga na escola após o período de remanejamento e matrícula digital, mas disse que a probabilidade dos responsáveis conseguirem vaga é pequena, "porque a procura é enorme!" . No entanto, em outro momento da entrevista, afirmou que pode "dar um jeitinho" e conseguir uma vaga para alguém que solicite diretamente a ele, à direção ou mesmo à CRE: "Fala aí com o Jean que o Jean dá um jeitinho. Às vezes tem, vêm umas, vêm uns pedidos da CRE assim que não tem como recusar." De acordo com o gestor, seriam frequentes casos de pais que o procuram "choram, se lamentam" e ele se "entristece" e realiza a matricula9.

Jean: Não, é assim, chora 'Não é que, estou com dificuldade com isso...' Ou então: 'Acabei de me separar, me mudei pra cá, vim com a cara e a coragem...' Aí o Jean se entristece...

Entrevistadora 2: Risos

Jean: Bobão, fica lá... Não! Peraí! Eu vou dar uma olhadinha melhor. Tá! Eu vou lá, procuro, procuro, procuro, procuro, procuro, procuro : 'Olha, eu tenho uma vaga aqui pra você no período da tarde.' 'Ah, muito obrigada, que-não-sei-o-quê, eu queria...'

Entrevistadora 2: Mas isso acontece muito, Jean?

Jean: Ih, direto!

Essas transferências não seriam esporádicas. Em 2014, Jean afirma que "toda a semana tem alunos entrando e saindo". Em 2016, o gestor continua assinalando que há muitas matrículas realizadas por transferência diretamente na escola. Os motivos que

\footnotetext{
${ }^{9}$ A primeira entrevista realizada com Jean foi objeto de análise no trabalho de Fernandes (2014).
} 
ROSISTOLATO, R.; PRADO, A. P. do; MUANIS, M; CERDEIRA, D. Burocracia educacional em interação com as famílias nos processos de matrícula escolar na cidade do Rio de Janeiro

levam os responsáveis a solicitar a transferência são mudança de endereço e mudança da escola particular para pública. Para exemplificar, Jean imita a fala de uma mãe solicitando a transferência, dizendo que seu filho é bonzinho e tem idade adequada à série. Essa menção demonstra que os pais lidam com a escola cientes da existência de um controle de entrada para o qual o comportamento do aluno e seu desempenho acadêmico seriam importantes fatores a serem declarados no momento de pleitear a vaga:

\footnotetext{
Entrevistadora:...já teve, você já fez matricula de transferência?

Jean: esse ano?

Entrevistadora: $e$

Jean: um monte

Entrevistadora: Por que motivo as famílias vêm? Assim, essas transferências que você já fez, né, pegando até agora...

Jean: Assim, muita gente tá vindo morar em [bairro da escola] acabei de me mudar de [bairro longe da escola] para [bairro da escola] (...) eu precisava de uma vaga para o meu filho, meu filho é bonzinho, meu filho tá na série certa, tá na idade certa, aí eu...
}

Por conta da quantidade de transferências, a CRE solicita que as escolas enviem semanalmente um quadro com as vagas disponíveis. Essas vagas seriam divididas, de acordo com Jean, entre a CRE e a escola, permitindo a ação direta do gestor que afirma que às vezes "acerta" e às vezes "erra" na matrícula. Segundo ele, haveria inclusive "brincadeiras" por parte da diretora perguntando quem teria matriculado "alunos bagunceiros" na escola. A "brincadeira" sugere que os gestores responsáveis pela matrícula atuam como gatekeepers (Noreisch, 2007), proporcionando uma seleção dos alunos que receberão as vagas, tendo em vista seu comportamento e seu desempenho escolar.

Jean: O quadro de vaga é aquele então vamos respeitar o quadro de vagas. Porque cada escola sabe a sua realidade, né? E assim, às vezes a gente acerta a matrícula, às vezes a gente erra também. Vem umas coisinhas fofas, opa!

Entrevistadora 2: Risos - Como assim?

Jean: Ô! - "Ô garoto! Pelo amor de Deus, tu entrou ontem, tu já tá batendo no garoto? Pelo amor de Deus!"

Jean: Quem matriculou, quem matriculou esse aluno aí? Pelo amor de Deus! Primeiro dia dele, tô conhecendo esse aluno hoje, ó!

Entrevistadora 1: Mas quem fala isso, a direção ou é a...

Jean: A direção. A direção da escola brigando, mas é tudo na brincadeira, né? Quem fez a matrícula? - Foi o Jean! Aí a outra pessoa: 'Ah, quem matriculou essas pérolas aí? É o Jean, lógico!' Vou deixar meu queridinho na rua? Ah, que é isso?

Entrevistadora 1: Mas ela reclama de determinados alunos, desse jeito? Jean: Não, ela reclama, sim! Reclama porque tem aluno que é bagunceiro mesmo, né? Tem. Isso tem em toda escola.

Entrevistadora1: ah, de bagunceiro, não em relação à nota?

Jean: Não, bagunceiro mesmo. Aí chega a nota sabe, é horrível! 
Jean menciona também uma negociação de vagas entre gestores, especialmente para "alunos bonzinhos" e conhecidos da diretora. Assinalar o comportamento do aluno é importante na hora de conseguir uma vaga. De acordo com ele, seria necessário ter cautela nesses pedidos posto que o atendimento a uma solicitação poderia gerar, como contrapartida, o recebimento, em outro momento, de um aluno cujo perfil é indesejado naquela escola.

Jean: Mas assim, é assim, de vez em quando tem assim, a diretora chega lá, vamos supor, você tem um aluno, um amigo da diretora conhece o aluno, é bonzinho, só que não tem vaga. Você entra em contato com a outra diretora, 'Escuta, você tem uma vaguinha pra mim de $6^{\circ}$ ano - por exemplo - de $6^{\circ}$ ano, não? $O$ aluno é bom, $o$ aluno é quietinho, é tranquilinho...' Ela: 'Ah, por acaso eu tenho sim. Manda ela vir aqui falar comigo.' A gente de vez em quando entra em contato sim pra pedir uma vaga ou outra, mas assim...

Entrevistadora 1: Durante o período...

Jean: Durante o ano letivo inteiro. Assim, é muito difícil a gente pedir vaga. Entrevistadora 1: Hmmm... Entendi.

Jean: Porque assim, tem que ser conhecido, né, pra você pedir uma vaga, você não tem intimidade pra ficar pedindo vaga. Depois fica devendo um favor, né? [...]

Jean: Olha, tu lembra aquela vaguinha que você me pediu? Agora eu preciso de uma. Só que ele é levado pra caramba, o moleque tocou o terror com todos nós aqui. Aí fica difícil, essa troca tá meio injusta, não tá?

A narrativa de Jean sobre as interações e negociações das vagas entre os gestores indicam práticas patrimonialistas nas matrículas. Há a possibilidade de pedir uma vaga para um aluno conhecido, "bom" e "quietinho" e esse pedido depende da relação pessoal estabelecida entre os gestores. Trata-se de um processo de troca de favores, algo típico em sistemas patrimonialistas. A questão que esse tipo de relação coloca para os sistemas republicanos está relacionada à negação da impessoalidade da distribuição de bens públicos. Há, conforme o relato de Jean, relações diferentes com os beneficiários das políticas públicas. Aqueles que estabelecem interações afetivas com o funcionário tendem a ser privilegiados em relação aos outros que seguem somente as regras estabelecidas.

As entrevistas com Jean, realizadas em 2014 e 2016, revelam que a ausência de regulamentação das transferências internas e matrículas iniciais presenciais nas unidades escolares permitem ações discricionárias que, em última instância, definem o perfil do aluno que conseguirá a vaga na escola. Esses resultados são convergentes com os estudos de Carvalho (2014), Costa, Prado \& Rosistolato (2013), Moreira (2014), Oliveira e Carvalho (2017) e Almeida (2019). Em todos esses estudos, há descrições de ações discricionárias e de práticas patrimonialistas na distribuição de bens públicos. 
ROSISTOLATO, R.; PRADO, A. P. do; MUANIS, M; CERDEIRA, D. Burocracia educacional em interação com as famílias nos processos de matrícula escolar na cidade do Rio de Janeiro

A escola gerenciada por Jean encontra-se na zona sul da cidade do Rio de Janeiro. Na sequência do texto, apresentaremos uma escola da zona norte. Descreveremos e analisaremos uma série de processos convergentes com os descritos na zona sul, o que revela regularidades relacionadas às práticas patrimonialistas e discricionárias desenvolvidas no decorrer dos processos de matrícula.

\subsection{A ESCOLA AZURITA}

A Escola Municipal Azurita está localizada na região norte da cidade do Rio de Janeiro. Tem 393 alunos distribuídos entre os quatro anos do $2^{\circ}$ segmento do ensino fundamental. Trata-se de uma escola que funciona em dois turnos, manhã e tarde, tem cinco salas e vinte e um professores.

A escola possui alunos que estão no nível IV do Indicador de nível socioeconômico das escolas da educação básica (Inse/Inep) ${ }^{10}$. Isso significa que, além de bens elementares, como dois ou três quartos para dormir e um banheiro, as famílias dos alunos têm uma geladeira, três ou mais telefones celulares e um ou dois televisores. A renda familiar mensal encontra-se entre 1,5 e 3 salários mínimos e seus responsáveis completaram o ensino médio ou o nível superior.

A escola Azurita recebe alunos cujos pais, em sua maioria, possuem nível de escolaridade mais elevado do que a média da CRE. Os professores são mais qualificados que a média da CRE (todos têm nível superior, mas a maioria tem especialização ou pósgraduação) e seu IDEB no segundo segmento é mais alto que a média da CRE e do município. O desempenho dos alunos na Prova Brasil em Língua Portuguesa e Matemática, em 2017, é superior a 97\% das escolas do município.

É importante salientar que, além desses dados objetivos, a escola possui reputação positiva no entorno em que está localizada. Tal reputação revela-se na demanda apresentada pelas vagas disponibilizadas pela escola. Segundo o relato da diretora entrevistada, a demanda é sempre muito maior do que a oferta efetiva, o que faz com que uma série de decisões sobre quem irá estudar na escola tenha que ser tomada.

\subsection{A VISÃO DAS FAMÍLIAS SOBRE A AÇÃO DOS GESTORES NA MATRÍCULA ESCOLAR}

\footnotetext{
10 Dados obtidos no site do INEP: www.inep.gov.br, acesso em 14 de maio de 2019.
} 
Em 2013, a aluna Ivana tinha 12 anos e cursava o 6o ano do Ensino Fundamental na Escola Azurita. Sua mãe, Carla, tinha 40 anos e era digitadora. Ela estudou até o 9o ano do ensino fundamental. Para Carla, sua filha é uma aluna muito boa, muito disciplinada e estuda em casa todos os dias sem ajuda.

Carla informou que Ivana estudava na Escola Turmalina, uma escola de baixo desempenho. No momento do remanejamento, a coordenadora pedagógica desse estabelecimento sugeriu que a mãe buscasse uma "escola melhor" para sua filha e indicou a Escola Azurita. A mãe também relatou que a coordenadora pedagógica a ajudou com a vaga, ligando para a diretora da Escola Azurita. Carla disse que só teve que ir à escola assinar o documento de matrícula. E completou: “A coordenadora Maria me ajudou muito, ela adora minha filha e acha que a Escola Azurita é uma escola mais forte e menos bagunçada, por isso que conseguiu a vaga para ela".

A aluna Miriam tinha 12 anos e, em 2013, cursava o $6^{\circ}$ ano do ensino fundamental na Escola Azurita. Sua mãe, Marcela, é zeladora de um estabelecimento de ensino e classifica a filha como uma aluna "regular", porque ela "é muito preguiçosa", mas "disciplinada" na escola. A mãe disse que a aluna costuma estudar em casa, uma hora diária, "cinco dias por semana", com a ajuda dela.

O ofício de zeladora de escola possibilitou à Marcela saber que a Escola Azurita "era a melhor escola dessa área", recebendo inclusive o "décimo quarto salário" como prêmio de desempenho ${ }^{11}$. Marcela nos apresentou sua visão sobre os critérios do remanejamento da escola em que trabalha para a Escola Azurita. Segundo ela, além do sorteio, haveria outros critérios para a seleção de novos alunos: funcionários, filhos de militares e alunos com irmãos teriam preferência nas vagas.

Entrevistadora: Assim perguntando, como é que a escola seleciona estes alunos para [as vagas].

Entrevistada: Aí tem as prioridades. Eu ganho porque eu sou funcionária, têm as que têm irmão, têm as filhas de militar, qualquer que tiver naquele parâmetro ali do quinto ano que já está indo para o sexto e que está neste contexto eles mandam. Entrevistadora: A questão do desempenho do aluno em sala de aula também conta? Entrevistada: Não.

Entrevistadora: Por exemplo, dentro daquela turma tem um aluno que tem uma nota boa...

\footnotetext{
11 Na época, a política de avaliação da Secretaria Municipal de Educação era composta pela Prova Rio, que avaliava anualmente os desempenhos dos estudantes da rede. As equipes das escolas que alcançavam as metas de desempenho estabelecidas com base no IDEB (Índice de Desenvolvimento da Educação Básica) e no IDE-Rio (Índice de Desenvolvimento da Educação do Rio de Janeiro) ganhavam o Prêmio Anual de Desempenho, conhecido como o décimo quarto salário.
} 


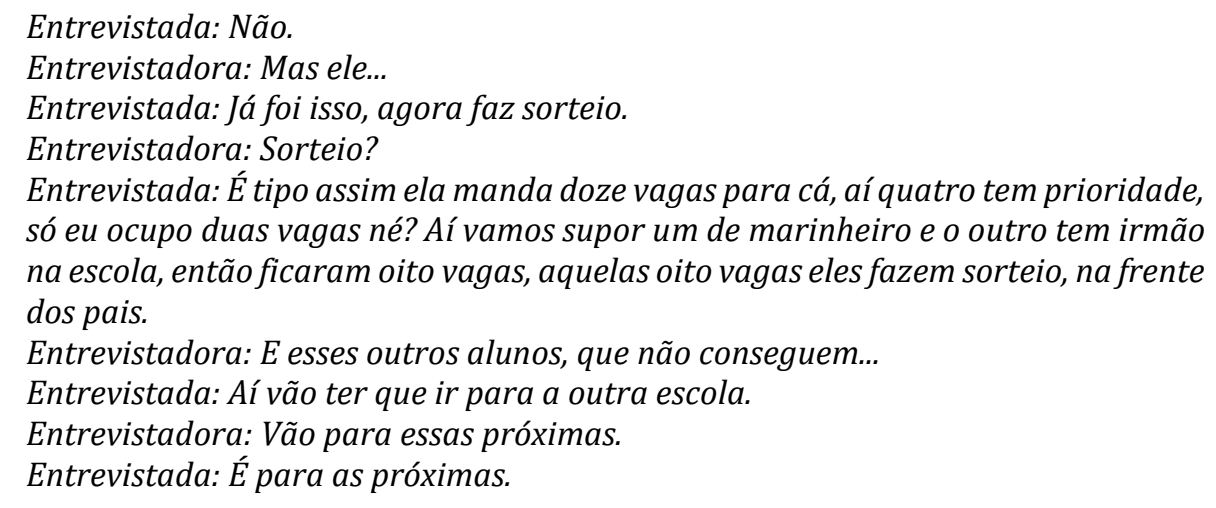

Marcela também nos explicou que conhecia a forma como a direção da Escola Azurita dividia as suas vagas. Era uma decisão feita na reunião de acompanhamento da CRE, em que a direção dividia as vagas entre duas escolas do polo, ambas com bom desempenho nas avaliações. Após o preenchimento das vagas por essas escolas, a direção disponibilizava as vagas restantes no sistema informatizado.

Entrevistadora: Tá. Eu só queria te fazer mais uma pergunta. No caso essas vagas que vêm da Azurita para a escola que você trabalha, a diretora que tem as vagas, né?

Entrevistada: Não. Elas fazem um acompanhamento na CRE; aí chega lá e fala assim: na X eu tenho dez, para Y eu tenho dez. Vai distribuindo entre escolas.

A pesquisadora perguntou como Marcela sabia dessas informações, e ela informou que trabalhou na escola por um mês. Os processos narrados pelas entrevistadas indicam ações discricionárias e patrimonialistas de gestores no período de remanejamento e inclusive antes dele, o que fica evidente quando a gestora age diretamente sugerindo que Carla buscasse uma escola melhor para a sua filha. A relação pessoal estabelecida entre a filha de Carla e a coordenadora pedagógica possibilitou o acesso à vaga na escola de prestígio do bairro. Já no caso de Marcela, o fato dela ser zeladora de uma escola e ter estabelecido relações pessoais na escola de prestígio possibilitou o conhecimento dos procedimentos para a matrícula e a obtenção da vaga. Assim como na escola analisada na zona sul, ter contato pessoal com os burocratas amplia a possibilidade de as famílias terem acesso às vagas mais disputadas. Novamente percebemos que a impessoalidade na distribuição de bens públicos não foi considerada em ambos os casos.

\subsection{A GESTORA E AS AÇÕES DISCRICIONÁRIAS}

A diretora Rebeca tem 54 anos. Ingressou na Escola Azurita em 1997 como 
ROSISTOLATO, R.; PRADO, A. P. do; MUANIS, M; CERDEIRA, D. Burocracia educacional em interação com as famílias nos processos de matrícula escolar na cidade do Rio de Janeiro

professora da sala de leitura e depois trabalhou como coordenadora pedagógica. No momento da entrevista, era diretora da escola.

Em relação ao processo de remanejamento, a diretora afirma que sua responsabilidade é informar à CRE o número de vagas disponíveis em sua escola. De acordo com ela, a Escola Azurita já teria recebido alunos de quatro unidades escolares diferentes, mas agora recebia apenas de duas por determinação da CRE. Segundo ela, os critérios que as escolas de $1^{\circ}$ segmento adotariam para direcionar os alunos a diferentes escolas de $2^{\circ}$ segmento seriam variáveis e dependentes das negociações realizadas a cada ano entre as diretoras e, por vezes, entre os outros atores presentes na comunidade escolar. Rebeca afirma que, em sua escola, o Conselho Escola Comunidade (CEC), presidido pelo diretor da escola, decide o critério: em alguns casos, sorteios; em outros, prioridade para os melhores alunos. Fica evidente, portanto, que a legislação do processo de matrícula dá margem para ações discricionárias que variam de acordo com a gestão de cada CRE e também com a gestão da escola.

Mesmo sem ingerência no remanejamento, a diretora diz que a procura por sua escola é "intensa". E a narrativa sobre sua gestão nos processos de transferência e matrículas iniciais sugere a presença de ações discricionárias no decorrer da distribuição de vagas. A diretora afirma que recebe os pais que desejam efetuar a matrícula na sua escola e os observa. Se os responsáveis demonstrarem "interesse em uma escola de qualidade" e não houver vagas, há duas possibilidades: ela anota os contatos do responsável em um "caderninho", para o caso de "aparecer uma vaga durante o ano" ou ela indica outras escolas que considera excelentes.

Rebeca: Porque aí eu fico olhando para cara da pessoa, eu olho o jeito de falar, eu vejo se é um bom responsável, eu olho se é aquela mãe que veio só pra pegar o filho $e$ "ralar peito" ou se é uma mãe que realmente está afim de uma escola de qualidade.

Entrevistadora: Uhum

Rebeca: Às vezes eu não posso fazer nada. Eu falo assim "olha mãe, vai lá na CRE, vê se você consegue alguma coisa... Não sei."

Entrevistadora: Uhum

Rebeca: Às vezes ela consegue... Indico boas escolas, porque às vezes eu não tenho, mas eu tenho excelentes escolas aqui no entorno.

Rebeca: Aí eu vou dizer pra você: 'Olha só, mãe, nós temos excelentes escolas na rede pública, experimente uma delas, porque a escola, são os alunos que fazem a escola!. Não tem mistério.' 'Eu quero aqui porque eu estudei aqui, meu filho estudou aqui, meu tio avô estudou aqui'... Eu falei: 'Bom, ou você tenta novamente no final do ano ou, se aparecer uma vaga durante o ano, o que é muito difícil...' aí eu anoto nome, endereço, telefone... Aí eu: 'Bom, se der eu ligo para você dizendo que tem' mas isso é muito difícil, muito difícil. 
As entrevistas com os pais de alunos que desejam matricular seus filhos na escola Azurita revelam ações discricionárias realizadas durante os processos de matrícula. A narrativa da gestora sugere também um espaço de ação discricionária nas transferências e matrículas iniciais. A gestora afirma que às vezes recebe pedidos de vagas oriundos da CRE e procura atendê-los. Neste caso, poderia até aumentar o número de alunos por turmas, desde que o estudante se encaixasse no perfil comportamental almejado pela escola. 0 ajuste pode ser realizado pelo uso da margem de $10 \%$ no número de alunos de cada turma, mas também pela troca de sala para uma de maior tamanho.

Entrevistadora: E a CRE também costuma pedir vaga para vocês, como é que funciona esse procedimento?

Rebeca: Também pede vaga, quando a gente tem a gente quebra o galho, consegue quebrar o galho, quando não... eu lamento, eu digo: 'serve outra série?' [...] Ai eu posso até aumentar o número, tá? Boto lá quadragésima primeira, quadragésima segunda...

Entrevistadora: Isso acontece com frequência, Rebeca?

Rebeca: Não... Algumas vezes. Não muito, mas acontece. Porque é a $4 a$ CRE, às vezes fica chato não atender a sua chefia. Entendeu? Já que eles são tão bacanas com a gente. Então às vezes: 'Eu não tenho.', 'Mas a mãe tá precisando muito', bem, aí vamos ver o que a gente consegue fazer. Às vezes a gente troca turma de sala, bota em uma sala maior que é pra poder atender. Porque tem isso, né? É o tamanho da sala que vai...

[...]

Rebeca: Se eu tiver, por exemplo uma turma de 38, que é o que tá na matrícula, eu boto mais 10\%, vou ficar com 41 alunos. Eu já ponho isso! Como é que eu vou botar mais um?! Mas... Se der a gente coloca, eu não tenho problema, basta eu ter carteira, cadeira e, digamos assim, é, condições de dar o mesmo acompanhamento a esse aluno, que eu dou aos demais. Pelo amor de Deus, você só não me arruma um aluno trabalhoso, aquele que você tem que dar... Realmente, além da instrução, você tem que dar... Às vezes chega no meio do ano: 'não, esse é tranquilo', aí esse eu recebo algumas vezes.

A menção ao fato de a quarta $C R E$ "ser bacana com a gente" - e, por isso a diretora sentir-se pressionada a atender seus pedidos - pode indicar que, no momento do remanejamento, quando a assessoria da CRE tem amplo poder de decisão acerca de quais escolas direcionarão alunos às escolas de $2^{\circ}$ segmento, a EM Azurita seja favorecida recebendo alunos selecionados de outras escolas do polo ${ }^{12}$.

As entrevistas apontam para ações discricionárias por parte da CRE no processo de remanejamento; e por parte da gestora, principalmente nas matrículas realizadas presencialmente. Conhecidas pelos pais dos alunos, estas ações buscam selecionar perfis

\footnotetext{
${ }^{12} \mathrm{O}$ fluxo não aleatório de alunos para as escolas de prestígio no remanejamento já foi demonstrado em Rosistolato et al, 2015.
} 
ROSISTOLATO, R.; PRADO, A. P. do; MUANIS, M; CERDEIRA, D. Burocracia educacional em interação com as famílias nos processos de matrícula escolar na cidade do Rio de Janeiro

de estudantes e de famílias para ingressar na escola. É desnecessário afirmar que essa prática de seleção de perfis além de não estar prevista em nenhuma legislação de matrícula é também ilegal porque beneficia alguns estudantes em detrimento de outros que não se enquadram no perfil desejado.

\section{CONSIDERAÇÕES FINAIS}

Neste artigo apresentamos, por um lado, as estratégias familiares para a obtenção de vagas nas escolas desejadas e, por outro, as ações da burocracia escolar na seleção dos alunos "desejáveis" para as escolas. Demonstramos que a flexibilidade das normas e critérios para a realização do remanejamento permite ações discricionárias das CREs e dos gestores. A CRE decide o número de vagas que as escolas de $1^{\circ}$ segmento utilizarão nas escolas de $2^{\circ}$ segmento no remanejamento. Os critérios usados para distribuir os alunos entre as escolas de destino são, por sua vez, definidos por cada escola. As entrevistas com os responsáveis indicam que conhecer ou buscar contato direto com a burocracia facilita a obtenção de vagas nas escolas mais disputadas. Além disso, mostram que a burocracia atua no encaminhamento dos melhores alunos para escolas de maior desempenho e melhor reputação.

Também demonstramos ações diretas dos gestores na seleção dos alunos. Ainda que seja necessário um estudo sobre a quantidade de transferências ocorridas ao longo do ano, as entrevistas sugerem que, longe de serem residuais, elas podem acontecer semanalmente e responder por um percentual significativo de matrículas nas escolas. As ações discricionárias dos gestores - que interagem com o público e "observam" as famílias para avaliar seu interesse na vida escolar dos filhos; ou buscam "acertar" na matrícula selecionando alunos "bonzinhos" - orientam e delimitam trajetórias formativas. Essas ações indicam que, para além da reprodução das desigualdades sociais, há, na rede de ensino do Rio de Janeiro, a produção de novas desigualdades pautadas por critérios especificamente escolares: comportamento e desempenho dos alunos.

\section{REFERÊNCIAS}

ALMEIDA, D. M. O. Ações dos gestores escolares no processo de matrícula em uma escola municipal do Rio de Janeiro. 2019. Dissertação (Mestrado) - Programa de Pós-Graduação em Educação, Universidade Federal do Rio de Janeiro, Rio de Janeiro, 2019. 
ROSISTOLATO, R.; PRADO, A. P. do; MUANIS, M; CERDEIRA, D. Burocracia educacional em interação com as famílias nos processos de matrícula escolar na cidade do Rio de Janeiro

BRANDÃO, Z.; MANDERLET, D; PAULA, L. de. A circularidade virtuosa: investigação sobre duas escolas no Rio de Janeiro. Cadernos de Pesquisa, 35(126), 747-758, 2005.

BRUEL, Ana Lorena; BARTHOLO, Tiago Lisboa. Inequality of educational opportunities in Rio de Janeiro public school system: transition between segments of elementary school. Revista Brasileira de Educação, Rio de Janeiro, v. 17, n. 50, p. 303-328, 2012.

CARVALHO, Julia Tavares. Segregação escolar e a burocracia educacional: uma análise da composição do alunado nas escolas municipais do Rio de Janeiro. 2014. Dissertação (Mestrado) - Programa de Pós-Graduação em Educação, Universidade Federal do Rio de Janeiro, Rio de Janeiro, 2014.

CHARRAD, M. Central and Local Patrimonialism: State-building in Kin-based Societies. ANNALS, AAPSS, 636, July 2011, pp 49-68.

COLEMAN, J. Report on Equality of Educational Opportunity. U.S. Government Printing Office for Department of Health, Education and Welfare, 1966.

COSTA, M. Prestígio e Hierarquia Escolar: Estudo de Caso entre Diferenças entre Escolas numa Rede Municipal. Revista Brasileira de Educação (Impresso). Volume 13, p. 455469, 2008.

COSTA, Marcio; PRADO, Ana Pires; ROSISTOLATO, R. Talvez se eu tivesse algum conhecimento...: caminhos possíveis em um sistema educacional público e estratificado. Interseções, Rio de Janeiro, v. 14, p. 165-193, 2013.

DEPARTMENT OF EDUCATION AND SCIENCE. The Plowden Report. Children and their Primary Schools. A Report of the Central Advisory Council for Education. London: Her Majesty's Stationery Office, 1967.

ENCARNAÇÃO, M. Nem sucesso, nem fracasso: uma abordagem etnográfica de uma escola. 2007. Dissertação (Mestrado em Sociologia) - PPGSA/IFCS/Universidade Federal do Rio de Janeiro, Rio de Janeiro.

ERMAKOFF. I. Patrimony and Collective Capacity: An Analytical Outline. ANNALS, AAPSS, 636, July 2011, pp. 182-203.

FERNANDES, I. M. de A. "É tudo uma questão de entendimento e de necessidade": uso de relações pessoais para acesso em uma escola da rede municipal do Rio de Janeiro. Monografia de concussão de curso de Pedagogia. Universidade Federal do Rio de Janeiro, 2014.

INED. “Population" et l'enseignement. Paris, PUF, 1970.

KISER, E.; SACKS, A. African Patrimonialism in historical perspective: Assessing decentralized and privatized tax administration. ANNALS, AAPSS, 636, July 2011, pp. 129-149.

HANSON, S. Plebiscitarian Patrimonialism in Putin's Russia: legitimating authoritarianism in a postideological era. ANNALS, AAPSS, 636, July 2011, pp. 32-48. 
LAHIRE, Bernard. Sucesso escolar nos meios populares: as razões do improvável. São Paulo: Ática, 1997.

LIPSKY, M. Street-Level Bureaucracy: dilemmas of the individual in public services. Russell Sage Foundation, NY, 1980.

LOTTA, G.S. Burocracia e Implementação de Políticas de Saúde. Rio de Janeiro: Fiocruz, 2015.

MAYNARD-MOODY, S.; MUSHENO, M. Cops, Teachers, Counselors - Stories from the Front Lines of Public Service. The University of Michigan Press Ann Arbor, 2003.

MOREIRA, A. M. Escolha e acesso às escolas municipais do Rio de Janeiro: Um exercício de navegação social. 2014. Dissertação (Mestrado em Educação) - Programa de PósGraduação em Educação, Universidade Federal do Rio de Janeiro, 2014.

NOGUEIRA, C. M. M.; RESENDE, T. DE F.; VIANA, M. J. B. Escolha do estabelecimento de ensino, mobilização familiar e desempenho escolar. Rev. Bras. Educ. [online].vol.20, n.62, pp.749-772, 2015.

NOREISH, K. (2007). Choice as a rule, exception and coincidence: parents'understandings of catchment areas in Berlin. Urban Studies, 44 (7), pp. 13071328.

OLIVEIRA, M.M.; CARVALHO, C.P. A implementação de uma política educacional de combate ao fracasso escolar: percepções e ações de agentes implementadores em uma escola municipal do Rio de Janeiro. In: PIRES, R.R.C. Implementação de políticas públicas e reprodução de desigualdades. Boletim de Análise Político Institucional. Brasília, IPEA, 2017.

PIRES DO PRADO, A. ¿“A escola funciona bem”? Participación y descentralización educativa en una favela de Río de Janeiro. Tese de Doutorado em Antropologia, Universitat Autonoma de Barcelona. Barcelona, 2006.

PIRES DO PRADO, A. Os diretores e a cultura de gestão. Um estudo nas escolas públicas do Rio de Janeiro. Revista Contemporânea de Educação, v. 4, p. 332-350, 2009.

PIRES R.; LOTTA G.; JUNIOR. Burocracias implementadoras e a (re)produção de desigualdades sociais: Perspectivas de análise no debate internacional. In: PIRES R.,

LOTTA, G.; OLIVEIRA V. E. (ORGS). Burocracia e Políticas Públicas no Brasil: Interseções Analíticas. Brasília, IPEA, Enap, 2018.

RIO DE JANEIRO. Resolução Secretaria Municipal de Educação n. 25, de 24 de outubro de 2017.

ROSISTOLATO, R.; PIRES DO PRADO, A,; COSTA, M. Escolha, acesso e permanência em escolas públicas da cidade do Rio de Janeiro: estratégias familiares em um espaço de 
ROSISTOLATO, R.; PRADO, A. P. do; MUANIS, M; CERDEIRA, D. Burocracia educacional em interação com as famílias nos processos de matrícula escolar na cidade do Rio de Janeiro

disputa. Relatório Final de Projeto de pesquisa financiado pela FAPERJ (Fundação Carlos Chagas Filho de Amparo à Pesquisa do Estado do Rio de Janeiro). Rio de Janeiro, 2014.

ROSISTOLATO, R. Choice and access to the best schools of Rio de Janeiro: a rite of passage. Vibrant, Virtual Braz. Anthr. vol.12 no.2 Brasília July/Dec. 2015.

ROSISTOLATO, R.; PIRES DO PRADO, A.; KOSLINSKI, M.; CARVALHO, J.; MOREIRA, A. Dinâmicas de matrícula em escolas públicas na cidade do Rio de Janeiro. ProPosições, vol. 27 no. 3 Campinas Sept./Dec. 2016.

ROSISTOLATO, R.; PIRES DO PRADO, A.; CERDEIRA, D.; MUANIS, M. Os procedimentos de matrícula escolar em questão: Uma proposta de análise da distribuição de oportunidades educacionais no Rio de Janeiro. Relatório de Pesquisa, Rio de Janeiro, 2018.

ZAGO, N. Quando os dados contrariam as previsões estatísticas: os casos de êxito escolar nas camadas socialmente desfavorecidas. Paidéia (Ribeirão Preto) [online]. vol.10, n.18, pp.70-80, 2000. 


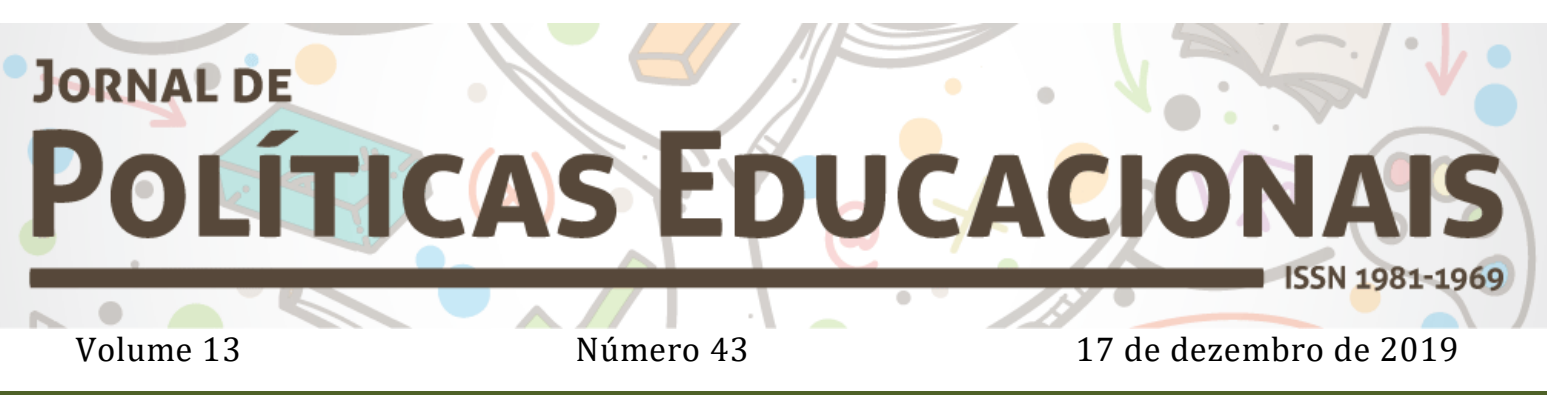

\begin{abstract}
(C)
SOREERIGHIS RESERVED O Copyright é retido pelo/a autor/a (ou primeiro co-autor) que outorga o direito da primeira publicação ao Jornal de Políticas Educacionais. Mais informação da licença de CreativeCommons encontram-se em http://creativecommons.org/licenses/by-nc-nd/2.5. Qualquer outro uso deve ser aprovado em conjunto pelo/s autor/es e pelo periódico.

JoRnal DE Políticas EdUCACIONAIS é uma publicação do Núcleo de PolíticasEducacionaisdo Setor de Educação da Universidade Federal do Paraná - NuPE/UFPR, em consórcio com a Linha de Pesquisa em Políticas Educacionais do Programa de Pós-Graduação em Educação - PPGE/UFPR, que aceita colaboração, reservando-se o direito de publicar ou não o material espontaneamente enviado à redação. As colaborações devem ser enviadas ao NuPE/UFPR, conforme orientações contidas nas páginas do periódico na internet: http://revistas.ufpr.br/ipe.
\end{abstract}

\author{
Indexação: \\ BBE - Biblioteca Brasileira de Educação (MEC/INEP) \\ Clase (Base de Datos Bibliográfica de Revistas de Ciencias Sociales y Humanidades) \\ Diadorim - Diretório de Política de Acesso Aberto das Revistas Científicas Brasileiras (IBICT) \\ Google Scholar \\ Index Copernicus \\ Portal de Periódicos (CAPES) \\ SER - Sistema Eletrônico de Revistas da Universidade Federal do Paraná (SER/UFPR) \\ Sumários de Revistas Brasileiras (FUNPEC-RP) \\ DRJI - Directory of Research Journals Indexing
}

(Periódico integralmente disponível apenas em via eletrônica)

Jornal de Políticas Educacionais / Núcleo de Políticas Educacionais da Universidade Federal do Paraná NuPE/UFPR - v.1, n. 1 (1ํㅗ semestre de 2007) - Curitiba: NuPE/UFPR.

Volume 13, número 43 - Dezembro de 2019

ISSN 1981-1969

1. Educação - Periódicos. 2. Política Educacional - Periódicos. I. NuPE/UFPR

Comitê Editorial:

Elisângela Scaff (UFPR)

Daniela de Oliveira Pires (UFPR)

Conselho Editorial:

Andréa Barbosa Gouveia (UFPR - Brasil), Cesar Tello (Universidad Nacional Tres Febrero, Argentina), Fernanda Saforcada (Universidad de Buenos Aires - UBA - Argentina), Gladys Beatriz Barreyro (USP Brasil), Gustavo Enrique Fischman, (Arizona State University - USA), Jefferson Mainardes (UEPG - Brasil), João Ferreira de Oliveira (UFG - Brasil), Juca Gil (UFRGS - Brasil), Luiz Souza Júnior (UFPB - Brasil), Ney 
ROSISTOLATO, R.; PRADO, A. P. do; MUANIS, M; CERDEIRA, D. Burocracia educacional em interação com as famílias nos processos de matrícula escolar na cidade do Rio de Janeiro

Cristina Monteiro de Oliveira (UFPA - Brasil), Nicolás Bentancur, (Universidad de la República de Uruguay), Robert Verhine (UFBA - Brasil), Rosana Cruz (UFPI - Brasil), Rubens Barbosa Camargo (USP - Brasil), Sebastián Donoso Díaz (Universidad de Talca - Chile), TheresaAdrião (UNICAMP - Brasil), Vera Peroni (UFRGS - Brasil).

Créditos e Agradecimentos:

Revisão de Língua Portuguesa, Abstract e Resumen: PROGRAMA DE APOIO ÀS PUBLICAÇÕES CIENTÍFICAS PERIÓDICAS DA UFPR

Arte e diagramação: TIAGO TAVARES (tiagotav@gmail.com)

Jornal de Políticas Educacionais

Universidade Federal do Paraná

Setor de Educação

Núcleo de Políticas Educacionais - NuPE/UFPR

Avenida Sete de Setembro, 2645

$2^{\circ}$ andar, Sala 213

80.230-010 - Curitiba - PR - Brasil

Tel.: 41-3535-6264

jpe@ufpr.br

http://revistas.ufpr.br/jpe 